\title{
Biphasic Mechanisms of Amphetamine Action at the Dopamine Terminal
}

\author{
Cody A. Siciliano, Erin S. Calipari, Mark J. Ferris, and Sara R. Jones \\ Department of Physiology and Pharmacology, Wake Forest School of Medicine, Winston-Salem, North Carolina 27157
}

In light of recent studies suggesting that amphetamine (AMPH) increases electrically evoked dopamine release ([DA $\left.]_{o}\right)$, we examined discrepancies between these findings and literature that has demonstrated AMPH-induced decreases in $[\mathrm{DA}]_{\mathrm{o}}$. The current study has expanded the inventory of AMPH actions by defining two separate mechanisms of AMPH effects on $[\mathrm{DA}]_{\mathrm{o}}$ at high and low doses, one dopamine transporter (DAT) independent and one DAT dependent, respectively. AMPH concentrations were measured via microdialysis in rat nucleus accumbens after intraperitoneal injections of 1 and $10 \mathrm{mg} / \mathrm{kg}$ and yielded values of $\sim 10$ and $200 \mathrm{~nm}$, respectively. Subsequently, voltammetry in brain slices was used to examine the effects of low (10 nM), moderate (100 nM), and high (10 $\mu \mathrm{M})$ concentrations of AMPH across a range of frequency stimulations (one pulse; five pulses, $20 \mathrm{~Hz} ; 24$ pulses, $60 \mathrm{~Hz}$ ). We discovered biphasic, concentrationdependent effects in WT mice, in which AMPH increased $[\mathrm{DA}]_{\mathrm{o}}$ at low concentrations and decreased $[\mathrm{DA}]_{\mathrm{o}}$ at high concentrations across all stimulation types. However, in slices from DAT-KO mice, $[\mathrm{DA}]_{\mathrm{o}}$ was decreased by all concentrations of AMPH, demonstrating that AMPH-induced increases in $[\mathrm{DA}]_{o}$ are DAT dependent, whereas the decreases at high concentrations are DAT independent. We propose that low AMPH concentrations are insufficient to disrupt vesicular sequestration, and therefore AMPH acts solely as a DAT inhibitor to increase $[\mathrm{DA}]_{0}$. When AMPH concentrations are high, the added mechanism of vesicular depletion leads to reduced $[\mathrm{DA}]_{\mathrm{o}}$. The biphasic mechanisms observed here confirm and extend the traditional actions of AMPH, but do not support mechanisms involving increased exocytotic release.

Key words: dopamine transporter; knock-out; nucleus accumbens; phasic; tonic; voltammetry

\section{Introduction}

Amphetamine $(\mathrm{AMPH})$ is used clinically for the treatment of attention deficit hyperactivity disorder and narcolepsy and is one of the most commonly prescribed psychostimulants (Bartholow, 2010). Due to high prescription rates and significant abuse potential, stimulants (including AMPH) are commonly used offlabel, with $1.2 \%$ of individuals aged $\geq 12$ years in the United States reporting prescription stimulant abuse (Substance Abuse and Mental Health Services Administration, 2008). AMPH exerts its rewarding and reinforcing effects primarily through its ability to increase extracellular dopamine (DA) levels (Di Chiara and Imperato, 1988). Although AMPH causes inhibition of DA uptake by competitively binding to the dopamine transporter (DAT), it induces much larger increases in extracellular DA than traditional DAT blockers because of its ability to enter DA terminals, cause the movement of DA out of vesicles, and release DA into the extracellular space via DAT-mediated reverse transport

Received Sept. 21, 2013; revised March 6, 2014; accepted March 12, 2014.

Author contributions: C.A.S., E.S.C., M.J.F., and S.R.J. designed research; C.A.S. performed research; C.A.S. analyzed data; C.A.S., E.S.C., M.J.F., and S.R.J. wrote the paper.

This work was funded by National Institutes of Health Grants R01 DA021325, R01 DA030161 (S.R.J.), P50 DA006634 (S.R.J., M.J.F.), T32 DA007246 and F31 DA031533 (E.S.C.), K99 DA031791 (M.J.F.), and T32 AA007565 (C.A.S.).

The authors declare no competing financial interests.

Correspondence should be addressed to Dr. Sara R. Jones, Department of Physiology and Pharmacology, Wake Forest School of Medicine, Medical Center Boulevard, Winston-Salem, NC 27157. E-mail: srjones@wakehealth.edu. DOI:10.1523/JNEUROSCI.4050-13.2014

Copyright $\odot 2014$ the authors $\quad 0270-6474 / 14 / 345575-08 \$ 15.00 / 0$
(Fleckenstein et al., 2007; Sulzer, 2011). In addition to robust elevations in extracellular DA, AMPH-induced movement of DA out of vesicles results in decreased exocytotic release. This phenomenon has been shown repeatedly and has historically been a defining characteristic of AMPH effects on the DA system (Sulzer and Rayport, 1990; Sulzer et al., 1993; Jones et al., 1998, 1999; John and Jones, 2007). In contrast, it has been proposed recently that exocytotic DA release may be increased by AMPH (Daberkow et al., 2013). If AMPH facilitates exocytotic release, this would require a revision of the established mechanisms of AMPH action.

Given the widespread use of AMPH, both clinically and offlabel, it is of critical importance to elucidate its exact mechanisms of action. The large body of AMPH literature which documents decreased exocytotic release as a sine qua non mechanism of AMPH action on the DA system has focused on high concentrations (Sulzer and Rayport, 1990; Sulzer et al., 1993; Jones et al., 1998, 1999; John and Jones, 2007), which may not be representative of brain concentrations present after acute administration of the drug in vivo. Thus, we assessed the concentration of AMPH reached in the brain in vivo after systemic administration of the drug via microdialysis and used fast scan cyclic voltammetry (FSCV) in brain slices to determine the effects of AMPH on electrically evoked DA levels ([DA $]_{\mathrm{o}}$ ) across a wide range of concentrations that encompassed the levels detected.

We found that concentrations of AMPH reached in vivo augmented $[\mathrm{DA}]_{\mathrm{o}}$. Using mice with a genetic deletion of the DAT 
(DAT-KO), we demonstrated that the augmentation was dependent on the interaction of AMPH with the DAT, suggesting that uptake inhibition, rather than increased exocytotic release, was responsible for the signal enhancement. Together, these findings show that the effects of AMPH on $[\mathrm{DA}]_{\mathrm{o}}$ are DAT dependent at low concentrations, which enhance $[\mathrm{DA}]_{\mathrm{o}}$ in wild-type (WT) mice, and DAT independent at high concentrations, which reduce $[\mathrm{DA}]_{\mathrm{o}}$ in both WT and DAT-KO mice. Thus, here we amend the established mechanisms of AMPH by delineating a novel, biphasic model of AMPH actions, characterized by a facilitation of $[\mathrm{DA}]_{\mathrm{o}}$ at low concentrations and vesicular depletioninduced attenuation of $[\mathrm{DA}]_{\mathrm{o}}$ at high concentrations.

\section{Materials and Methods}

Animals. Male DAT-KO mice (Giros et al., 1996) on a C57BL/6J background (bred in house for 10 generations) and WT C57BL/6J mice (The Jackson Laboratory) were maintained on a $12 \mathrm{~h}$ light/dark cycle (lights on at 6:00 A.M. lights on; lights off at 6:00 P.M.) with food and water available ad libitum. Male Sprague Dawley rats (Harlan Laboratories) weighing between 400 and $450 \mathrm{~g}$ were maintained on a $12 \mathrm{~h}$ reverse light/dark cycle (lights on at 3:00 P.M.; lights off at 3:00 A.M.), with food and water available ad libitum. All animals were maintained according to the $\mathrm{Na}$ tional Institutes of Health guidelines in Association for Assessment and Accreditation of Laboratory Animal Care-accredited facilities. The experimental protocol was approved by the Institutional Animal Care and Use Committee at Wake Forest School of Medicine.

Microdialysis. All micodialysis experiments were performed in male Sprague Dawley rats. Animals were anesthetized with isoflurane $(2-3 \%$ in oxygen). Microdialysis guide cannulae (CMA/Microdialysis) were stereotaxically implanted above the nucleus accumbens (NAc) core (anteroposterior, $+1.2 \mathrm{~mm}$; lateral, $2.0 \mathrm{~mm}$; ventral, $6.0 \mathrm{~mm}$ ). Concentric microdialysis probes ( $2 \mathrm{~mm}$ membrane length; CMA/Microdialysis) were inserted the day before recording. The probes were continuously perfused at $1 \mu \mathrm{l} / \mathrm{min}$ with artificial CSF (aCSF), $\mathrm{pH} 7.4$, containing the following (in mM): $148 \mathrm{NaCl}, 2.7 \mathrm{KCl}, 1.2 \mathrm{CaCl}_{2}$, and $0.85 \mathrm{MgCl}_{2}$. Baselines were collected for at least $2 \mathrm{~h}$ before administration of an AMPH (1 or $10 \mathrm{mg} / \mathrm{kg}$ ) intraperitoneal challenge. Brain dialysate samples were collected in $20 \mathrm{~min}$ intervals throughout the time course of AMPH effects (200 min after injection).

ELISA. An AMPH ELISA kit (Abnova) was used to measure AMPH in brain dialysate samples from animals injected intraperitoneally with either 1 or $10 \mathrm{mg} / \mathrm{kg}$ AMPH. The AMPH standards of the manufacturer and negative and positive controls were run on each plate. A $10 \mu \mathrm{l}$ aliquot of diluted samples was pipetted manually into the plate wells in duplicate. The ELISAs were then run according to the instructions of the manufacturers. The samples were incubated with a $100 \mu \mathrm{l}$ dilution of enzyme (horseradish peroxidase)-labeled AMPH derivative in microplate wells coated with fixed amounts of oriented high-affinity purified polyclonal antibody, and the mixture was incubated at room temperature for $60 \mathrm{~min}$ in the dark. After incubation, the plate was washed six times with deionized $\mathrm{H}_{2} \mathrm{O}$ to remove any unbound sample or drug-enzyme conjugate. The chromogenic substrate was then added $(100 \mu \mathrm{l} /$ well $)$, and the plate was incubated for $30 \mathrm{~min}$ in the dark. After substrate incubation, the reaction was halted with the addition of an acid-based stop solution (100 $\mu \mathrm{l} /$ well). The plate was read using a Spectra max plus plate reader equipped with a $450 \mathrm{~nm}$ filter (Molecular Devices).

Calibration curves were plotted as log concentration versus the logit of the ratio of the absorbance at each concentration divided by the absorbance of the zero standards. AMPH concentrations were estimated from the calibration curve using the ratio of the mean absorbance of the sample to the mean absorbance of the zero standards.

In vitro voltammetry. All FSCV experiments were performed in male WT or DAT-KO mice. FCSV was used to characterize presynaptic DA release in the NAc core region. A vibrating tissue slicer was used to prepare $400-\mu \mathrm{m}$-thick coronal brain sections containing the NAc. The tissue was immersed in oxygenated aCSF containing the following (in m): $126 \mathrm{NaCl}, 2.5 \mathrm{KCl}, 1.2 \mathrm{NaH}_{2} \mathrm{PO}_{4}, 2.4 \mathrm{CaCl}_{2}, 1.2 \mathrm{MgCl}_{2}, 25$ $\mathrm{NaHCO}_{3}, 11$ glucose, and $0.4 \mathrm{~L}$-ascorbic acid, $\mathrm{pH}$ was adjusted to 7.4.
Once sliced, the tissue was transferred to testing chambers containing aCSF at $32^{\circ} \mathrm{C}$, which flowed at $1 \mathrm{ml} / \mathrm{min}$. A carbon fiber microelectrode (100-200 $\mu \mathrm{m}$ length, $7 \mu \mathrm{m}$ radius) and bipolar stimulating electrode were placed in close proximity in the NAc core. Extracellular DA was recorded by applying a triangular waveform $(-0.4$ to +1.2 to $-0.4 \mathrm{~V}$ vs $\mathrm{Ag} / \mathrm{AgCl}, 400 \mathrm{~V} / \mathrm{s}$ ) to the recording electrode and scanning every $100 \mathrm{~ms}$.

DA release was evoked by one pulse, five pulses at $20 \mathrm{~Hz}$, or 24 pulses at $60 \mathrm{~Hz}(300 \mu \mathrm{A}, 4 \mathrm{~ms}$, monophasic for all stimulations) applied to the tissue every $5 \mathrm{~min}$. These stimulation parameters were selected to model the different in vivo firing patterns of DA neurons; one-pulse stimulations are thought to mimic tonic-like signaling while five-pulse, $20 \mathrm{~Hz}$ and 24-pulse, $60 \mathrm{~Hz}$ stimulations are thought to mimic phasic-like signaling (Zhang et al., 2009; Daberkow et al., 2013). One-pulse stimulations were applied to the tissue every 5 min until a stable baseline was established (three collections within 10\% variability). Subsequently, fivepulse and 24-pulse stimulations were applied to the slice to establish a baseline at these stimulation parameters. To confirm that the stimulation parameters were not altering $[\mathrm{DA}]_{\mathrm{o}}$ throughout the experiment, onepulse stimulations were recorded again after each change in the experimental parameters. After predrug measures were taken, either 10 or 100 nM concentrations of AMPH were bath applied to the slice. One-pulse stimulations were repeated until DA levels reached stability ( $\sim 40 \mathrm{~min})$. After stabilization, the multiple-pulse stimulation parameters were performed as described above. Both the 10 and $100 \mathrm{~nm}$ groups were then raised to a $10 \mu \mathrm{M}$ concentration and allowed to stabilize before undergoing an identical stimulation protocol to the one described for the lower doses.

Data analysis. For all analysis of FSCV data, Demon Voltammetry and Analysis software was used (Yorgason et al., 2011). Recording electrodes were calibrated by recording responses (in electrical current; nanoamperes) to a known concentration of DA $(3 \mu \mathrm{M})$ using a flow-injection system. This was used to convert electrical current to DA concentration. Voltammetric data were reported as $[\mathrm{DA}]_{\mathrm{o}}$ normalized as a percentage of the predrug, one-pulse stimulation from each slice.

Statistics. GraphPad Prism (version 5; GraphPad Software) was used to statistically analyze datasets and create graphs. Release data were subject to a repeated-measures two-way ANOVA with AMPH and stimulation parameters as the factors. When main effects were obtained $(p<0.05)$, differences between groups were tested using a Bonferroni's post hoc test. AMPH brain concentration time courses were analyzed with a one-way ANOVA. When significant main effects were observed $(p<0.05)$, differences across time were tested using a Tukey's post hoc test.

\section{Results}

\section{Extracellular concentrations of AMPH}

In rats, after a $1 \mathrm{mg} / \mathrm{kg}$ intraperitoneal injection of $\mathrm{AMPH}$, a one-way ANOVA revealed a main effect of time on brain AMPH levels $\left(F_{(10,30)}=5.184, p<0.001 ; n=4\right.$; Fig. $\left.1 A\right)$. Tukey's post hoc analysis revealed that levels were significantly elevated from time 0 at $60(p<0.001), 80(p<0.01), 100(p<0.05)$, and $140(p<$ $0.05)$ min after injection. The mean concentration of AMPH at the peak of the time course was $10.25 \pm 1.625 \mathrm{nM}$.

After a $10 \mathrm{mg} / \mathrm{kg}$ intraperitoneal injection of AMPH, a oneway ANOVA revealed a main effect of time on AMPH levels $\left(F_{(11,35)}=12.68, p<0.0001 ; n=4\right.$; Fig. $\left.1 B\right)$. Tukey's post hoc analysis revealed that levels were significantly increased from time 0 at $40(p<0.001), 60(p<0.001)$, and $80(p<0.05) \mathrm{min}$ after injection. The mean concentration of AMPH at the peak of the time course was $197 \pm 22.417 \mathrm{nM}$.

\section{AMPH increased $[\mathrm{DA}]_{\mathrm{o}}$ at low concentrations and decreased $[\mathrm{DA}]_{\mathrm{o}}$ at high concentrations in WT mice}

Having shown in vivo that extracellular concentrations of AMPH after acute administration are substantially lower than concentrations typically examined in vitro (Sulzer and Rayport, 1990; Sulzer et al., 1993; Jones et al., 1998, 1999), we hypothesized that discrepancies between the study by Daberkow et al. (2013) and 

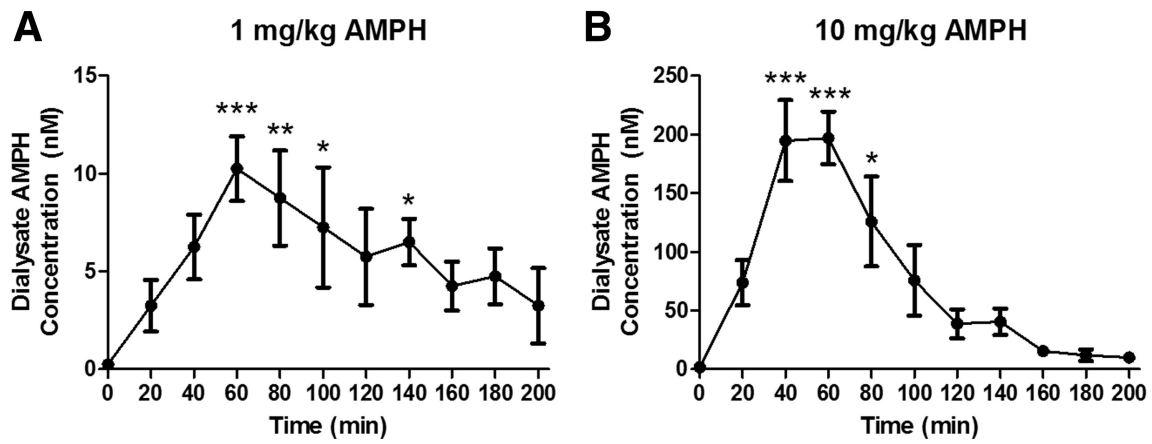

Figure 1. AMPH brain levels after 1 and $10 \mathrm{mg} / \mathrm{kg}$ intraperitoneal injection. AMPH levels were quantified in brain dialysate samples over a $200 \mathrm{~min}$ period after an intraperitoneal AMPH injection of $1 \mathrm{mg} / \mathrm{kg}(\boldsymbol{A})$ or $10 \mathrm{mg} / \mathrm{kg}(\boldsymbol{B})$. ELISA was used to quantify the levels of AMPH present in samples. $A$, After $1 \mathrm{mg} / \mathrm{kg}$ intraperitoneal injection of AMPH, brain AMPH levels were significantly increased, with the mean peak of AMPH brain concentrations equaling $10.25 \pm 1.625 \mathrm{~nm} . \boldsymbol{B}, A 10 \mathrm{mg} / \mathrm{kg}$ intraperitoneal AMPH injection resulted in elevations in AMPH brain levels, with the mean peak concentration equaling $197 \pm 22.417 \mathrm{~nm}$. ${ }^{*} p<0.05 \mathrm{vs}$ time 0 ; ${ }^{* *} p<0.01$ vs time $0 ;{ }^{* * *} p<0.001$ vs time 0 .

previous in vitro literature resulted from differences in extracellular AMPH concentrations and sought to determine the effects of $\mathrm{AMPH}$ on $[\mathrm{DA}]_{\mathrm{o}}$ across a wide range of concentrations that encompass AMPH levels detected during our microdialysis experiment, as well as concentrations used in previous in vitro work. Although brain concentrations of AMPH after acute administration were measured in rats to allow for comparison with previous literature (Daberkow et al., 2013), the effects of these concentrations were assessed in brain slices from mice to allow for the use of the DAT-KO strain, which is not available in rats.

After bath application of $10 \mathrm{nM}$ AMPH in slices from WT mice, $[\mathrm{DA}]_{\mathrm{o}}$ was assessed after one pulse, five pulses at $20 \mathrm{~Hz}$, and 24 pulses at $60 \mathrm{~Hz}$ stimulations compared with their predrug measurements (Fig. 2A,D). A two-way repeated-measures ANOVA revealed a main effect of stimulation parameters on $[\mathrm{DA}]_{\mathrm{o}}\left(F_{(2,21)}=53.83, p=0.0001 ; n=9\right)$. Additionally, there was a main effect of AMPH on $[\mathrm{DA}]_{\mathrm{o}}\left(F_{(1,21)}=24.69, p=\right.$ $0.0001)$. Bonferroni's post hoc analysis revealed significant AMPH-induced increases in $[\mathrm{DA}]_{\mathrm{o}}$ at one-pulse $(p<0.05)$ and 24 -pulse stimulations $(p<0.01)$. There was not a significant interaction between $\mathrm{AMPH}$ and stimulation parameters $\left(F_{(2,21)}=\right.$ $1.476, p=0.2512$ ).

Previous in vitro studies examined AMPH concentrations in the $100 \mathrm{nM}$ to $10 \mu \mathrm{M}$ range (John and Jones, 2007; Ferris et al., 2011, 2012; Calipari et al., 2013). Therefore, we examined changes in $[\mathrm{DA}]_{\mathrm{o}}$ in response to concentrations that are representative of previous in vitro work. Consistent with previous work (Ferris et al., 2012), a two-way repeated-measures ANOVA revealed that there was no effect of AMPH on $[\mathrm{DA}]_{\mathrm{o}}$ after bath application of $100 \mathrm{nM}$ concentrations in slices from WT animals $\left(F_{(1,13)}=0.8135, p=0.3824 ; n=6\right.$; Fig. $\left.2 B, E\right)$. Additionally, there was a main effect of stimulation parameters on $[D A]_{0}$ $\left(F_{(2,13)}=11.34, p=0.0012\right)$ but no interaction between AMPH and stimulation parameters $\left(F_{(2,13)}=1.639, p=0.2319\right)$.

Consistent with previous in vitro work using highconcentration AMPH, at $10 \mu \mathrm{M}$ concentrations in WT slices, a two-way repeated-measures ANOVA revealed a main effect of AMPH on $[\mathrm{DA}]_{\mathrm{o}}\left(F_{(1,21)}=12.74, p=0.0018 ; n=8\right.$; Fig. $\left.2 C, F\right)$. Additionally, a two-way repeated-measures ANOVA revealed a main effect of stimulation parameters on $[\mathrm{DA}]_{\mathrm{o}}\left(F_{(2,21)}=16.34\right.$, $p=0.0001)$. Bonferroni's post hoc analysis revealed significant $\mathrm{AMPH}$-induced decreases in $[\mathrm{DA}]_{\mathrm{o}}$ at 24-pulse stimulations $(p<0.01)$.

\section{AMPH-induced increases in $[\mathrm{DA}]_{\mathrm{o}}$ found at low concentrations are dependent on the DAT}

Having demonstrated AMPH-induced increases in $[\mathrm{DA}]_{\mathrm{o}}$ at low concentrations, we sought to determine the mechanism by which $[\mathrm{DA}]_{\mathrm{o}}$ was increased using DAT-KO mice. AMPH is highly lipophilic, which allows it to cross the cell membrane and interact with intracellular components even in the absence of the DAT (Thoenen et al., 1968; Liang and Rutledge, 1982); thus, differences between DAT-KO and WT animals are likely attributable to the interaction of AMPH with the DAT and not its ability to enter the cell. We hypothesized that, if AMPH-induced increases in $[\mathrm{DA}]_{\mathrm{o}}$ are mediated by the DAT, no increase would be observed in DAT-KO animals. Alternatively, if AMPH facilitates exocytotic release, increases in $[\mathrm{DA}]_{\mathrm{o}}$ would be observed even in the absence of the DAT.

After bath application of $10 \mathrm{~nm} \mathrm{AMPH}$, we assessed [DA] following the stimulation parameters described above. Contrary to results from WT animals, a two-way repeated-measures ANOVA revealed that $10 \mathrm{nM}$ AMPH decreased [DA] in brain slices from DAT-KO animals $\left(F_{(1,21)}=6.270, p=0.0206 ; n=8\right.$; Fig. $3 A, D)$. Additionally, there was a main effect of stimulation parameters on $[\mathrm{DA}]_{\mathrm{o}}\left(F_{(2,21)}=34.97, p=0.0001\right)$, although there was no interaction between AMPH and stimulation parameters $\left(F_{(2,21)}=0.5832, p=0.5669\right)$.

After application of $100 \mathrm{nM}$ AMPH to brain slices from DAT-KO animals, a two-way repeated-measures ANOVA revealed a main effect of AMPH on $[\mathrm{DA}]_{\mathrm{o}}\left(F_{(1,21)}=17.79, p=\right.$ $0.0002 ; n=11)$, as well as a main effect of stimulation parameters on $[\mathrm{DA}]_{\mathrm{o}}\left(F_{(2,21)}=29.05, p=0.0001\right.$; Fig. $\left.3 \mathrm{~B}, E\right)$. Notably, Bonferroni's post hoc analysis revealed significant AMPH-induced decreases in $[\mathrm{DA}]_{\mathrm{o}}$ only at 24 -pulse stimulations $(p<0.01)$. There was not an interaction between AMPH and stimulation parameters $\left(F_{(2,30)}=0.7223, p=0.4939\right)$.

A two-way repeated-measures ANOVA revealed a main effect of $10 \mu \mathrm{M}$ AMPH on $[\mathrm{DA}]_{\mathrm{o}}$ in DAT-KO mice $\left(F_{(1,30)}=68.13, p=\right.$ $0.0001 ; n=11)$ and a main effect of stimulation parameters on $[D A]_{\mathrm{o}}\left(F_{(2,21)}=18.22, p=0.0001\right.$; Fig. 3C,F $)$. Bonferroni's post hoc analysis revealed significant AMPH-induced decreases in $[\mathrm{DA}]_{\mathrm{o}}$ at one-pulse $(p<0.01)$, five-pulse $(p<0.001)$, and 24-pulse $(p<$ $0.001)$ stimulations. There was not an interaction between AMPH and stimulation parameters $\left(F_{(2,30)}=2.038, p=0.1480\right)$.

We then compared the AMPH concentration-response curves for WT and DAT-KO animals to determine differences in AMPH-induced effects on [DA] o between strains (Fig. 4). After one-pulse stimulations, a two-way repeated-measures ANOVA revealed a main effect of $\operatorname{strain}\left(F_{(1,46)}=16.01, p=0.0002\right)$ and concentration $\left(F_{(2,46)}=21.37, p=0.0001\right)$ on $[\mathrm{DA}]_{\mathrm{o}}$, as well as a significant interaction between AMPH concentration and strain $\left(F_{(2,46)}=5.218, p=0.0091\right.$; Fig. $\left.4 A\right)$. Bonferroni's post hoc analysis revealed a significant difference between strains at $10 \mathrm{nM}$ $(p<0.01)$ and $100 \mathrm{nM}(p<0.01)$ concentrations of AMPH, whereas $10 \mu \mathrm{M}$ was not different. These results suggest that the $\mathrm{AMPH}$-induced increases in $[\mathrm{DA}]_{\mathrm{o}}$ at low concentrations are a result of the interaction of AMPH with the DAT.

After five-pulse, $20 \mathrm{~Hz}$ stimulations, a two-way repeatedmeasures ANOVA revealed a main effect of strain $\left(F_{(1,48)}=\right.$ 


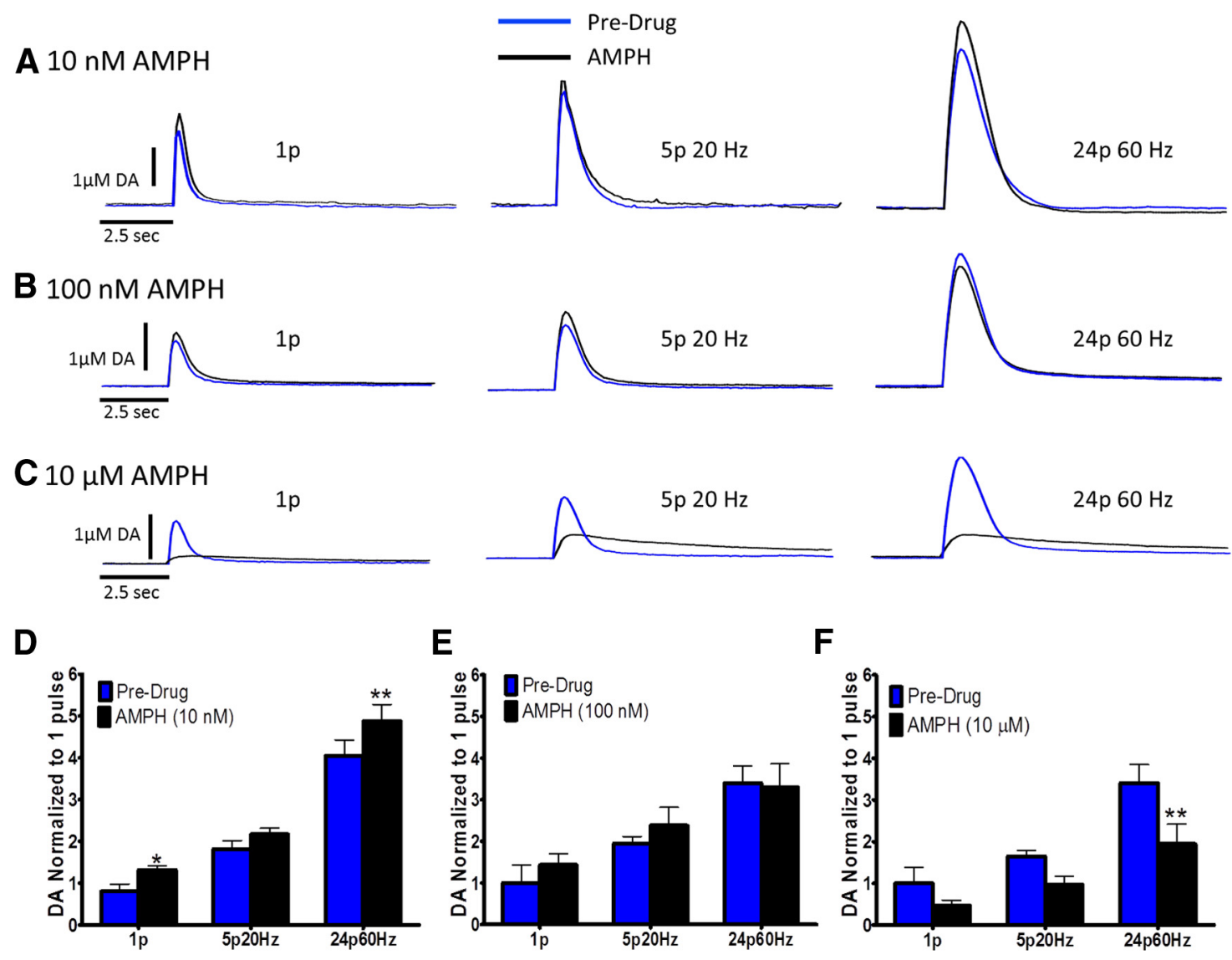

Figure 2. AMPH increases evoked DA at low concentrations and decreases exocytotic release at high concentrations in WT animals. The effect of bath-applied AMPH on evoked DA release was determined over multiple stimulation parameters [one pulse (1p); five pulses (5p) at $20 \mathrm{~Hz} ; 24$ pulses (24p) at $60 \mathrm{~Hz}$ ]. Effects of AMPH were consistent across stimulation parameters for all concentrations. Representative traces of evoked DA release before (predrug; blue) and after bath application of $10 \mathrm{nм}(\boldsymbol{A}), 100 \mathrm{nм}(\boldsymbol{B})$, and $10 \mu \mathrm{M}(\boldsymbol{C})$ AMPH (black). Group data indicating a significant AMPH-induced increase in DA levels after application of $10 \mathrm{~nm}(\boldsymbol{D})$, but not $100 \mathrm{nм}(\boldsymbol{E})$, AMPH. $\boldsymbol{F}$, Group data indicating a significant decrease in DA levels after application of $10 \mu \mathrm{M}$ AMPH. ${ }^{*} p<0.05$ vs predrug; ${ }^{* *} p<0.01$ vs predrug.

8.093, $p=0.0065)$ and concentration $\left(F_{(2,48)}=11.33, p=\right.$ $0.0001)$ but no interaction $\left(F_{(2,48)}=2.530, p=0.0903\right.$; Fig. $\left.4 B\right)$. Bonferroni's post hoc analysis revealed a significant difference between strains at $10 \mathrm{nM} \mathrm{AMPH}(p<0.05)$.

After 24-pulse, $60 \mathrm{~Hz}$ stimulations, a two-way repeatedmeasures ANOVA revealed no effect of strain $\left(F_{(1,47)}=3.482\right.$, $p=0.0559)$ but a main effect of concentration $\left(F_{(2,47)}=15.50\right.$, $p=0.0001)$, as well as a significant interaction $\left(F_{(2,47)}=\right.$ 3.904, $p=0.0270$; Fig. $4 C$ ). Bonferroni's post hoc analysis revealed a significant difference between strains at the $10 \mathrm{~nm}$ concentration of AMPH $(p<0.01)$.

Repeated stimulations do not alter DA release over time To ensure that the observed changes in $[\mathrm{DA}]_{\mathrm{o}}$ were AMPH induced and not attributable to repeated high-frequency, multiplepulse stimulations over time, identical stimulation parameters were performed in the absence of AMPH in a separate set of WT and DAT-KO animals. We observed no effect of time on $[\mathrm{DA}]_{\mathrm{O}}$ in slices from WT $\left(F_{(1,24)}=0.2624, p=0.6132 ; n=9\right)$ or DAT-KO $\left(F_{(1,15)}=0.3913, p=0.5410 ; n=6\right)$ animals (data not shown).

Fenfluramine decreased [DA $]_{\mathrm{o}}$ across all concentrations, stimulation parameters, and genotypes

To give additional support to the hypothesis that the effects of $\mathrm{AMPH}$ on $[\mathrm{DA}]_{\mathrm{o}}$ are DAT dependent and independent at low and high concentrations, respectively, we examined the effects of fenfluramine, a serotonin releaser with similar effects on vesicular DA storage but with limited DAT affinity, on $[\mathrm{DA}]_{\mathrm{o}}$. Because of the lipophilicity of fenfluramine, it is able to cross the plasma membrane, enter the cell, and interact with DA vesicles without using uptake transporters (Spinelli et al., 1988). We hypothesized that, if AMPH-induced increases in $[\mathrm{DA}]_{\mathrm{o}}$ at low concentrations were DAT dependent, we would not observe increases with fenfluramine. Additionally, if AMPH-induced decreases in $[\mathrm{DA}]_{\mathrm{o}}$ at high concentrations are DAT independent, fenfluramine would induce similar decreases in $[\mathrm{DA}]_{\mathrm{o}}$ at high concentrations. We examined the effects of fenfluramine on $[\mathrm{DA}]_{\mathrm{o}}$ in WT and DAT-KO animals across a concentration-response curve and a range of stimulation parameters consistent with those used in AMPH experiments.

In brain slices from WT animals, a two-way repeatedmeasures ANOVA revealed a main effect of fenfluramine across a range of stimulation parameters at $10 \mathrm{nM}\left(F_{(1,9)}=17.35, p=\right.$ $0.0024 ; n=4$; Fig. $5 A), 100 \mathrm{nM}\left(F_{(1,9)}=8.857, p=0.0156 ; n=4\right.$; Fig. $5 B)$, and $10 \mu \mathrm{M}\left(F_{(1,12)}=39.45, p=0.0001 ; n=5\right.$; Fig. $\left.5 C\right)$, whereby fenfluramine decreased $[\mathrm{DA}]_{\mathrm{o}}$. Bonferroni's post hoc analysis revealed a significant decrease in $[D A]_{o}$ at 24-pulse stimulations after $10 \mathrm{nM}$ fenfluramine $(p<0.05)$ and at five-pulse $(p<0.05)$ and 24-pulse $(p<0.001)$ stimulations for $10 \mu \mathrm{M}$ concentrations.

Similarly, in slices from DAT-KO animals, a two-way repeated-measures ANOVA revealed a main effect of fenflu- 


\section{A $10 \mathrm{nM} \mathrm{AMPH}$}
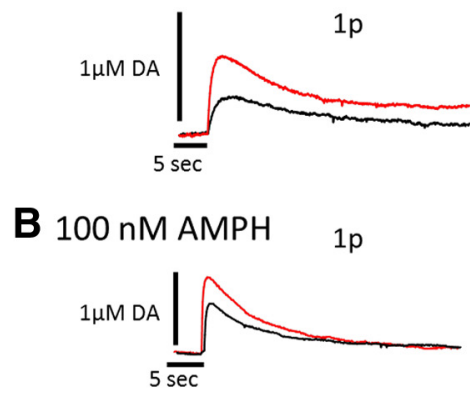

C $10 \mu \mathrm{MAMPH}$

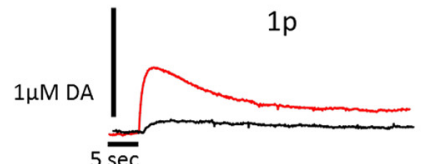

D

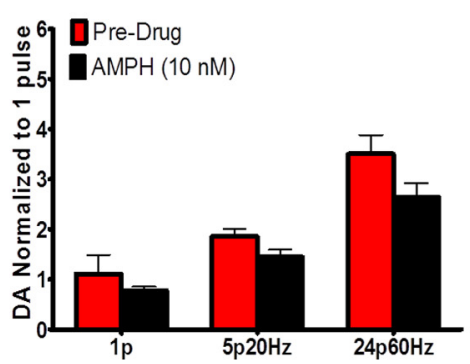

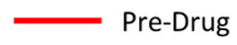

AMPH

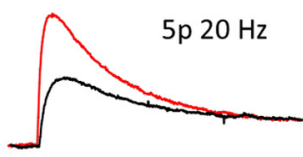

$5 p 20 \mathrm{~Hz}$
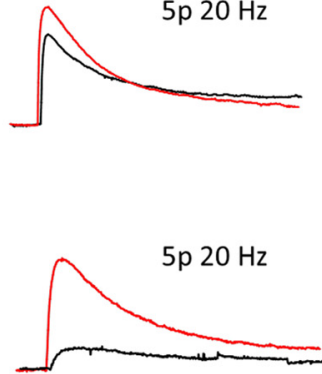

$\mathbf{E}$

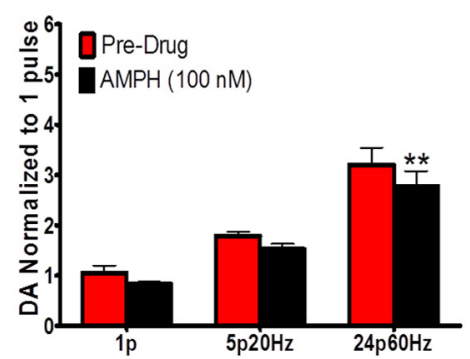

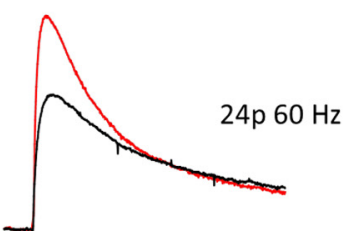
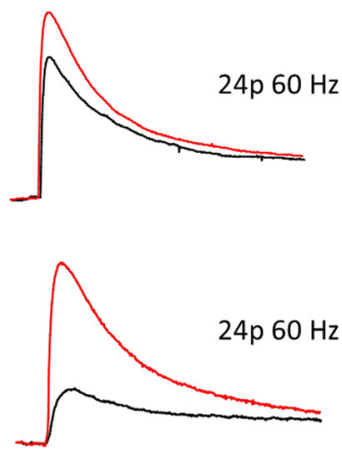

$\mathbf{F}$

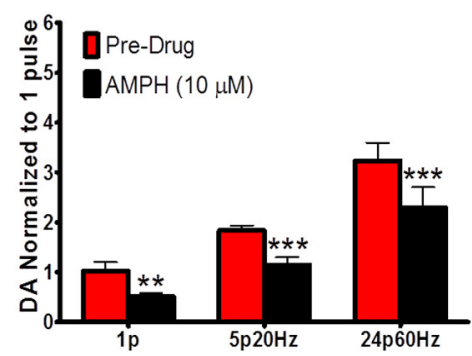

Figure 3. AMPH decreases evoked DA levels in DAT-KO animals. The effect of bath-applied AMPH on evoked DA levels was determined over multiple stimulation parameters [one pulse (1p); five pulses (5p) at $20 \mathrm{~Hz}$; 24 pulses (24p) at $60 \mathrm{~Hz}$ ]. Stimulation parameters had no effect on the pharmacological actions of AMPH. Representative traces of evoked DA release before (predrug; red) and after bath application of $10 \mathrm{~nm}(\boldsymbol{A}), 100 \mathrm{~nm}(\boldsymbol{B})$, and $10 \mu \mathrm{m}(\boldsymbol{C})$ AMPH (black). $\boldsymbol{D}$, Group data indicating AMPH-induced decreases in evoked DA at $10 \mathrm{~nm}$. Although ANOVA revealed a main effect of AMPH on evoked DA levels, Bonferroni's post hoc analysis did not reveal a significant effect at any of the stimulation parameters. $\boldsymbol{E}$, Group data demonstrating AMPH-induced decreases in DA levels after the application of $100 \mathrm{~nm} \mathrm{AMPH.F,} \mathrm{Group} \mathrm{data} \mathrm{indicating} \mathrm{an} \mathrm{AMPH-induced} \mathrm{decrease} \mathrm{in} \mathrm{DA} \mathrm{levels} \mathrm{at} 10 \mu \mathrm{m} .{ }^{* *} p<0.01 \mathrm{vs}$ predrug; ${ }^{* * *} p<0.001$ vs predrug.
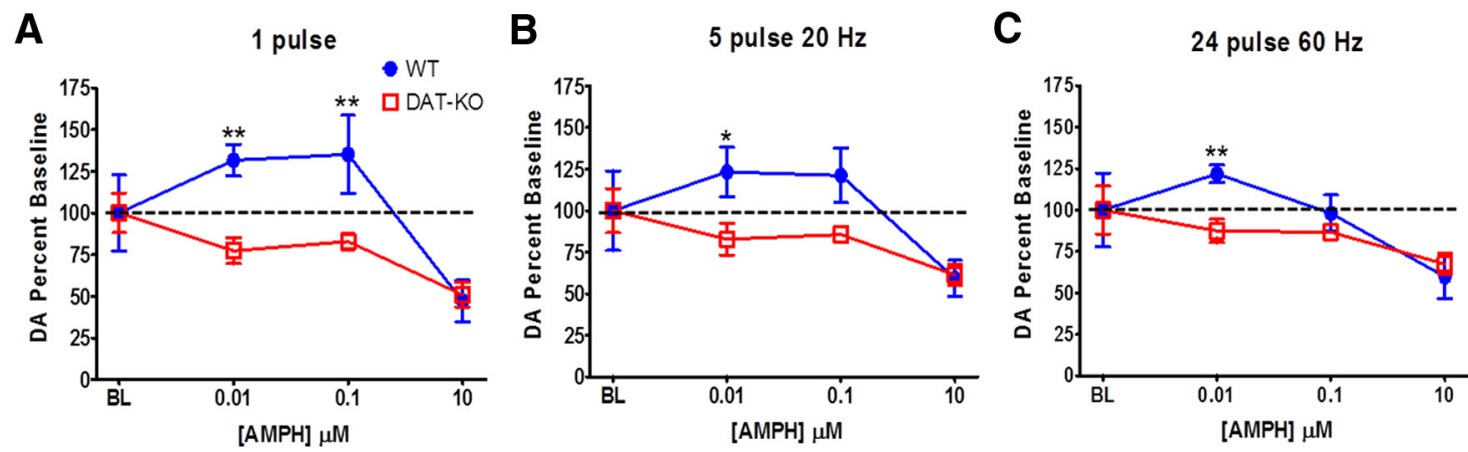

Figure 4. AMPH-induced increases in evoked DA levels are dependent on the DAT. AMPH was bath applied to brain slices from WT (blue) or DAT-KO (red) animals. Evoked DA levels were determined across a concentration-response curve for AMPH (10 nm, $100 \mathrm{~nm}, 10 \mu \mathrm{m})$ and multiple stimulation parameters (one pulse; five pulses at $20 \mathrm{~Hz}$; $24 \mathrm{pulses}$ at $60 \mathrm{~Hz}$ ). $\boldsymbol{A}$, Concentrationresponse curve for AMPH after one-pulse stimulations. AMPH-induced increases in DA levels at 10 and $100 \mathrm{~nm}$ are dependent on the DAT, whereas AMPH-induced decreases at $10 \mu \mathrm{m}$ are not. $\boldsymbol{B}$, Concentration-response curve for AMPH after five-pulse stimulations. C, Concentration-response curve for AMPH after 24-pulse stimulations. ${ }^{*} p<0.05$ vs DAT-K0 animals; ${ }^{* *} p<0.01$ vs DAT-K0 animals.

ramine across a range of stimulation parameters after application of $10 \mathrm{nM}\left(F_{(1,6)}=10.98, p=0.0161 ; n=3\right.$; Fig. $\left.5 D\right), 100 \mathrm{nM}$ $\left(F_{(1,6)}=13.03, p=0.0112 ; n=3\right.$; Fig. $\left.5 E\right)$, and $10 \mu \mathrm{M}\left(F_{(1,11)}=\right.$ $35.58, p=0.0001 ; n=5$; Fig. $5 F)$ fenfluramine, with decreases in $[\mathrm{DA}]_{\mathrm{o}}$. Bonferroni's post hoc analysis revealed a significant fenfluramine-induced decrease in $[D A]_{o}$ at 24-pulse stimulations after $10 \mathrm{~nm}$ fenfluramine $(p<0.05)$ and at five-pulse $(p<0.05)$ and 24-pulse $(p<0.001)$ stimulations for $10 \mu \mathrm{M}$ concentrations.
These findings further support the hypothesis that AMPH effects are DAT dependent and independent at low and high concentrations, respectively.

\section{Discussion}

Here we demonstrate that AMPH mechanisms differ based on the extracellular concentration of AMPH. Specifically, we found a biphasic effect of AMPH, in which low concentrations in- 
A

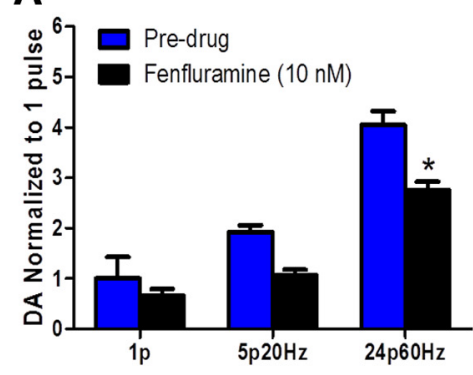

D

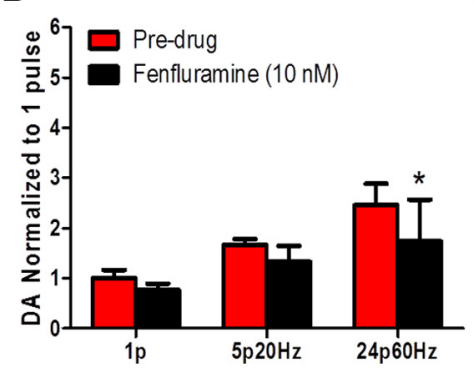

B

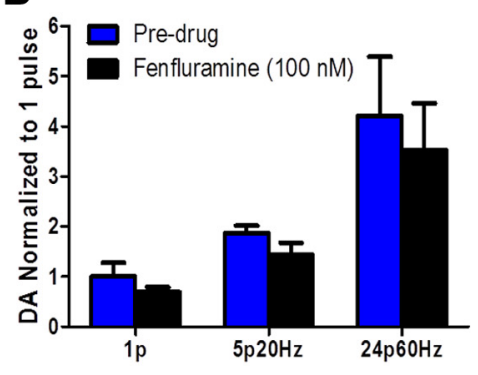

$\mathrm{E}$

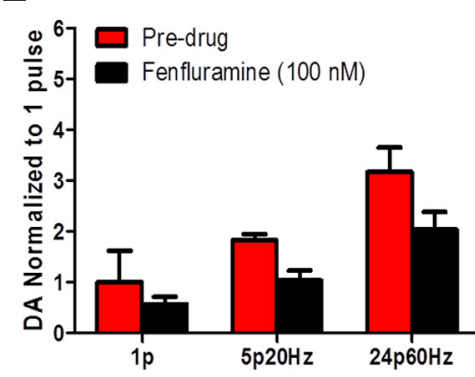

C

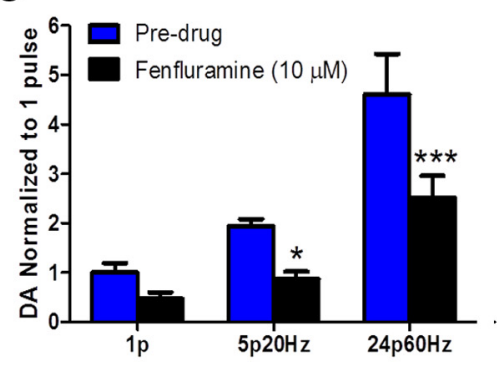

$F$

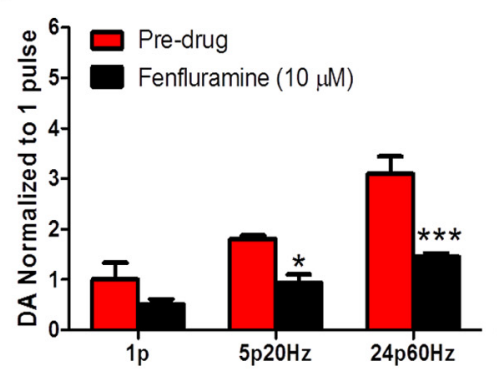

Figure 5. Fenfluramine decreases evoked DA levels across all concentrations, stimulation parameters, and genotypes. Fenfluramine was bath applied to brain slices from WT (A-C) or DAT-KO $(\boldsymbol{D}-\boldsymbol{F})$ animals. Evoked DA levels were determined across a concentration-response curve for fenfluramine (10 nм, $100 \mathrm{~nm}, 10 \mu \mathrm{M})$ and multiple stimulation parameters [one pulse (1p); five pulses (5p) at $20 \mathrm{~Hz} ; 24$ pulses (24p) at $60 \mathrm{~Hz}$. In WT animals, fenfluramine reduced DA levels across all stimulation parameters after $10 \mathrm{~nm}(\boldsymbol{A}), 100 \mathrm{~nm}(\boldsymbol{B})$, and $10 \mu \mathrm{m}(\boldsymbol{C})$ concentrations. Although ANOVA revealed a main effect of fenfluramine on evoked DA levels at $100 \mathrm{~nm}$, Bonferroni's post hoc analysis did not reveal a significant effect at any of the stimulation parameters. In DAT-K0 animals, DA levels were decreased across all stimulation parameters after $10 \mathrm{~nm}(\boldsymbol{D}), 100 \mathrm{~nm}(\boldsymbol{E})$, and $10 \mu \mathrm{m}(\boldsymbol{F})$ concentrations of fenfluramine. Although ANOVA revealed a main effect of fenfluramine on evoked DA levels at $100 \mathrm{~nm}$, Bonferroni's post hoc analysis did not reveal a significant effect at any of the stimulation parameters. ${ }^{*} p<0.05$ vs predrug; ${ }^{* * *} p<0.001$ vs predrug.

creased $[D A]_{o}$ and high concentrations decreased $[D A]_{o}$ in WT animals. In addition, we did not observe an AMPH-induced augmentation of $[\mathrm{DA}]_{\mathrm{o}}$ in DAT-KO animals, demonstrating that increases in $[\mathrm{DA}]_{\mathrm{o}}$ are dependent on AMPH actions at the DAT. The opposite effects of low and high concentrations of AMPH on $[D A]_{o}$ in WT animals may help to explain previous literature demonstrating divergent outcomes of acute AMPH administration on DA-mediated behaviors, in which low doses facilitated performance on attention and learning tasks and high doses disrupted performance (de Wit et al., 2002; Idris et al., 2005).

AMPH-induced depletion of DA vesicles, resulting in decreased $[\mathrm{DA}]_{\mathrm{o}}$, has been shown repeatedly in in vitro studies and is traditionally thought to be a hallmark of AMPH actions (Jones et al., 1998, 1999; Fleckenstein et al., 2007; Sulzer, 2011). Recently, Daberkow et al. (2013) extended these findings, showing that $\mathrm{AMPH}$ increased $[\mathrm{DA}]_{\mathrm{o}}$ in vivo and interpreted the increase as augmented exocytotic release. In an attempt to reconcile the apparent discrepancy between the in vitro and in vivo findings, we determined the extracellular concentrations of AMPH reached in vivo to allow the selection of physiologically relevant concentrations to assess in vitro.

We found that, in rats, 1 and $10 \mathrm{mg} / \mathrm{kg}$ intraperitoneal injections of AMPH correspond to peak concentrations of $\sim 10$ and $200 \mathrm{nM}$ AMPH in the extracellular space, respectively. Increases in $[D A]_{o}$ shown in vivo (Daberkow et al., 2013) were measured 10 min after AMPH injection. The time course of AMPH brain concentrations shows that, at this time point, AMPH levels were $\sim 30$ $\mathrm{nM}$, and our in vitro data suggest that this concentration would produce an increase in $[D A]_{o}$, similar to the effect demonstrated in vivo. At the time when higher concentrations were observed (40 min), $[\mathrm{DA}]_{\mathrm{o}}$ is returning to baseline in vivo, which is consistent with effects seen at the concentrations $(\sim 100-300 \mathrm{nM})$ applied here and in previous studies (Ferris et al., 2012; Calipari et al., 2013). Indeed, previous studies examining the effects of
AMPH in vitro have shown that $[D A]_{o}$ is not decreased until concentrations meet or exceed $1 \mu \mathrm{M}$ (Ferris et al., 2012), which is higher than the range of concentrations reached in vivo (Daberkow et al., 2013). We showed that AMPH does facilitate $[D A]_{\mathrm{o}}$ in vitro at low concentrations, demonstrating that the discrepancies between the two models are indeed attributable to different extracellular concentrations of AMPH. Although methamphetamine has been shown previously to exhibit similar concentration-dependent effects on DA cell bodies in the midbrain (Branch and Beckstead, 2012), this is the first examination of the effects of low AMPH concentrations in the terminal regions.

Furthermore, our data show that the biphasic, concentrationdependent effects of AMPH involve both DAT-dependent and -independent mechanisms. Using DAT-KO mice, it was determined that the DAT was required for AMPH-induced increases in $[\mathrm{DA}]_{\mathrm{o}}$. AMPH-induced increases are completely absent in DAT-KO animals, demonstrating that AMPH acts via the DAT to elevate $[\mathrm{DA}]_{\mathrm{o}}$. Although AMPH enters the cell primarily via transporter-mediated movement (Bönisch, 1984), it is highly lipophilic and readily traverses the cell membrane (Thoenen et al., 1968; Liang and Rutledge, 1982). Thus, differences between DAT-KO and WT animals are likely not attributable to a differential ability of AMPH to enter the cell. This is highlighted by the reductions in $[\mathrm{DA}]_{\mathrm{o}}$ in DAT-KO mice at high concentrations, an effect that demonstrates that vesicular depletion is independent of AMPH actions at the DAT. The hypothesis that AMPH effects at low and high concentrations are DAT dependent and independent, respectively, was further supported by our findings that fenfluramine, an AMPH-like releaser with low DAT affinity, decreased $[\mathrm{DA}]_{\mathrm{o}}$ across all concentrations. However, in DAT-KO mice, although AMPH is likely causing the movement of DA from vesicles into the cytoplasm, this DA is not released into the extracellular space, and the reduction in $[\mathrm{DA}]_{\mathrm{o}}$ may be a combi- 
nation of vesicular depletion and subsequent degradation of DA that has accumulated within the cytoplasm.

The DAT-dependent and -independent effects observed here suggest that AMPH acts as a DA uptake inhibitor at low concentrations, whereas at high concentrations, vesicular depletion is also present. In voltammetric measurements, as in the brain, the maximal extracellular concentration of DA is a result of the opposing processes of release and uptake; thus, increases in $[D A]_{o}$, as seen in the current study and previous work (Daberkow et al., 2013), can be attributed to either increased release or uptake inhibition (Wightman et al., 1990; Yorgason et al., 2011). Indeed, drugs such as nomifensine, which inhibit the DAT but have not been shown to have any release capabilities, increase $[\mathrm{DA}]_{\mathrm{o}}$ (Wightman and Zimmerman, 1990; Ferris et al., 2011). Therefore, although it has been suggested that AMPH increases $[\mathrm{DA}]_{\mathrm{o}}$ through facilitated exocytotic release (Daberkow et al., 2013), AMPH-induced increases in $[D A]_{o}$ are more likely a result of the previously validated mechanism of AMPH as a competitive uptake inhibitor. This hypothesis is supported by the findings of the current study showing that AMPH-induced increases in $[\mathrm{DA}]_{\mathrm{o}}$ are DAT-dependent.

At high concentrations, AMPH also causes uptake inhibition, which could lead to increases in $[D A]_{o}$; however, we observed decreases in $[D A]_{o}$ at high concentrations. This could be attributable to factors such as AMPH-induced disruption of cellular membranes or vesicular depletion, which has been shown previously to play a role in the actions of AMPH on $[\mathrm{DA}]_{\mathrm{o}}$ (Sulzer and Rayport, 1990; Sulzer et al., 1993). One hypothesis is that AMPHinduced depletion of DA vesicles at high concentrations is a result of AMPH entering vesicles via diffusion across the vesicular membrane or transport through the vesicular monoamine transporter-2 (VMAT-2), where its properties as a weak base disrupt $\mathrm{pH}$ gradients, leading to the movement of DA out of vesicles and into the cytoplasm (Fleckenstein et al., 2007; Sulzer, 2011). The lack of DA depletion observed here in WT mice at low concentrations may be a result of insufficient concentrations of AMPH within the vesicles to disrupt vesicular sequestration. Indeed, previous cell culture studies demonstrated that, at low to moderate concentrations of AMPH, $\mathrm{pH}$ gradients are $90 \%$ intact (Floor and Meng, 1996) and do not result in movement of DA out of vesicles (Teng et al., 1998). Thus, AMPH primarily acts as an uptake inhibitor at low concentrations, making its actions resemble those of a blocker.

An alternative, although not opposing, hypothesis is that high AMPH concentrations reduce quantal size by decreasing DA uptake into vesicles via blockade of VMAT-2, resulting in decreased $[D A]_{\text {o }}$ (Wallace and Connell, 2008). Although AMPH may be interacting with VMAT-2 even at the low concentrations tested here, it is likely that effects at the DAT will predominate at these concentrations because the $K_{\mathrm{i}}$ of AMPH for the inhibition of DA uptake at the DAT is $34 \mathrm{~nm}$ compared with $2.71 \mu \mathrm{M}$ at the VMAT-2 (Philippu and Beyer, 1973; Rothman and Baumann, 2003). Thus, it is likely that, at low concentrations, AMPH is inhibiting DA uptake at the DAT but having minimal effects on the VMAT-2, resulting in increased $[D A]_{0}$. However, as concentrations are increased, blockade of the VMAT-2 becomes more prominent, resulting in decreased $[D A]_{o}$.

Additionally, $[\mathrm{DA}]_{\mathrm{o}}$ was reduced at low and moderate concentrations in DAT-KO animals. As discussed above, the current findings and previous studies indicate that the AMPH concentrations tested here are not sufficient to decrease exocytotic release. One explanation is that DAT-KO terminals, which are unable to take up DA from synapses and repackage it into vesicles and are therefore dependent on DA synthesis for release, have reduced $[D A]_{o}$ at low concentrations due to the effects of AMPH on DA synthesis (Sotnikova et al., 2006). It is possible that AMPH raises cytoplasmic DA levels via blockade of the VMAT-2, resulting in substrate inhibition of tyrosine hydroxylase. Cytoplasmic DA buildup may occur in this situation for two reasons: (1) the lack of DAT-mediated reverse transport of DA into the synapse in these animals; and (2) the inhibitory effects of AMPH on monoamine oxidase activity (Sulzer, 2011). Regardless, both scenarios would likely lead to an increased inhibition of tyrosine hydroxylase activity and subsequent reductions in $[\mathrm{DA}]_{\mathrm{o}}$ because of the dependence of DAT-KO mice on synthesis of new DA for release.

Here we show biphasic, concentration-dependent actions of AMPH, which suggest that AMPH acts as a blocker at low concentrations and a releaser at high concentrations, making concentration a critical determinant of the acute effects of the compound. This is particularly relevant when considering the neurochemical outcomes of human AMPH use, because lowdose therapeutic and high-dose abuse-relevant administration may have different mechanisms of acutely elevating DA levels, potentially leading to different long-term consequences. Given the shift in mechanism of AMPH from blocker to releaser, depending on concentration, it will be important to amend, but not discard, the traditional view of AMPH mechanisms and its effects on DA neurotransmission.

\section{References}

Bartholow M (2010) Top 200 prescription drugs of 2009. Pharmacy Times website. Available at: http://www.pharmacytimes.com/publications/issue/2010/May 2010/RxFocusTopDrugs-0510. Accessed November 28, 2011.

Bönisch H (1984) The transport of (+)-amphetamine by the neuronal noradrenaline carrier. Naunyn Schmiedebergs Arch Pharmacol 327:267-272. CrossRef Medline

Branch SY, Beckstead MJ (2012) Methamphetamine produces bidirectional, concentration-dependent effects on dopamine neuron excitability and dopamine-mediated synaptic currents. J Neurophysiol 108:802-809. CrossRef Medline

Calipari ES, Ferris MJ, Salahpour A, Caron MG, Jones SR (2013) Methylphenidate amplifies the potency and reinforcing effects of amphetamines by increasing dopamine transporter expression. Nat Commun 4:2720. CrossRef Medline

Daberkow DP, Brown HD, Bunner KD, Kraniotis SA, Doellman MA, Ragozzino ME, Garris PA, Roitman MF (2013) Amphetamine paradoxically augments exocytotic dopamine release and phasic dopamine signals. J Neurosci 33:452-463. CrossRef Medline

de Wit H, Enggasser JL, Richards JB (2002) Acute administration of d-amphetamine decreases impulsivity in healthy volunteers. Neuropsychopharmacology 27:813-825. CrossRef Medline

Di Chiara G, Imperato A (1988) Drugs abused by humans preferentially increase synaptic dopamine concentrations in the mesolimbic system of freely moving rats. Proc Natl Acad Sci U S A 85:5274-5278. CrossRef Medline

Ferris MJ, Mateo Y, Roberts DC, Jones SR (2011) Cocaine-insensitive transporters with intact substrate transport produced by self-administration. Biol Psychiatry 69:201-207. CrossRef Medline

Ferris MJ, Calipari ES, Mateo Y, Melchior JR, Roberts DC, Jones SR (2012) Cocaine self-administration produces pharmacodynamic tolerance: differential effects on the potency of dopamine transporter blockers, releasers and methylphenidate. Neuropsychopharmacology 37:1708-1716. CrossRef Medline

Fleckenstein AE, Volz TJ, Riddle EL, Gibb JW, Hanson GR (2007) New insights into the mechanism of action of amphetamines. Annu Rev Pharmacol Toxicol 47:681-698. CrossRef Medline

Floor E, Meng L (1996) Amphetamine releases dopamine from synaptic vesicles by dual mechanisms. Neurosci Lett 215:53-56. CrossRef Medline

Giros B, Jaber M, Jones SR, Wightman RM, Caron MG (1996) Hyperlocomotion and indifference to cocaine and amphetamine in mice lacking the dopamine transporter. Nature 379:606-612. CrossRef Medline

Idris NF, Repeto P, Neill JC, Large CH (2005) Investigation of the effects of 
lamotrigine and clozapine in improving reversal-learning impairments induced by acute phencyclidine and D-amphetamine in the rat. Psychopharmacology 179:336-348. CrossRef Medline

John CE, Jones SR (2007) Voltammetric characterization of the effect of monoamine uptake inhibitors and releasers on dopamine and serotonin uptake in mouse caudate-putamen and substantia nigra slices. Neuropharmacology 52:1596-1605. CrossRef Medline

Jones SR, Gainetdinov RR, Wightman RM, Caron MG (1998) Mechanisms of amphetamine action revealed in mice lacking the dopamine transporter. J Neurosci 18:1979-1986. Medline

Jones SR, Joseph JD, Barak LS, Caron MG, Wightman RM (1999) Dopamine neuronal transport kinetics and effects of amphetamine. J Neurochem 73:2406-2414. CrossRef Medline

Liang NY, Rutledge CO (1982) Comparison of the release of [ $\left.{ }^{3} \mathrm{H}\right]$ dopamine from isolated corpus striatum by amphetamine, fenfluramine and unlabelled dopamine. Biochem Pharmacol 31:983-992. CrossRef Medline

Philippu A, Beyer J (1973) Dopamine and noradrenaline transport into subcellular vesicles of the striatum. Naunyn Schmiedebergs Arch Pharmacol 278:387-402. CrossRef Medline

Rothman RB, Baumann MH (2003) Monoamine transporters and psychostimulant drugs. Eur J Pharmacol 479:23-40. Medline

Sotnikova TD, Caron MG, Gainetdinov RR (2006) DDD mice, a novel acute mouse model of Parkinson's disease. Neurology 67:S12-S17. Medline

Spinelli R, Fracasso C, Guiso G, Garattini S, Caccia S (1988) Disposition of $(-)$-fenfluramine and its active metabolite, $(-)$-norfenfluramine in rat: a single dose-proportionality study. Xenobiotica 18:573-584. CrossRef Medline

Substance Abuse and Mental Health Services Administration (2008) National Survey on Drug Use and Health. Available at: http://www.oas. samhsa.gov/nhsda.htm. Accessed September 17, 2013.
Sulzer D (2011) How addictive drugs disrupt presynaptic dopamine neurotransmission. Neuron 69:628-649. CrossRef Medline

Sulzer D, Rayport S (1990) Amphetamine and other psychostimulants reduce $\mathrm{pH}$ gradients in midbrain dopaminergic neurons and chromaffin granules: a mechanism of action. Neuron 5:797-808. CrossRef Medline

Sulzer D, Maidment NT, Rayport S (1993) Amphetamine and other weak bases act to promote reverse transport of dopamine in ventral midbrain neurons. J Neurochem 60:527-535. CrossRef Medline

Teng L, Crooks PA, Dwoskin LP (1998) Lobeline displaces $\left[{ }^{3} \mathrm{H}\right]$ dihydrotetrabenazine binding and releases $\left[{ }^{3} \mathrm{H}\right]$ dopamine from rat striatal synaptic vesicles: comparison with d-amphetamine. J Neurochem 71:258-265. CrossRef Medline

Thoenen H, Hürlimann A, Haefely W (1968) Mechanism of amphetamine accumulation in the isolated perfused heart of the rat. J Pharm Pharmacol 20:1-11. CrossRef Medline

Wallace LJ, Connell LE (2008) Mechanisms by which amphetamine redistributes dopamine out of vesicles: a computational study. Synapse 62 : 370-378. CrossRef Medline

Wightman RM, Zimmerman JB (1990) Control of dopamine extracellular concentration in rat striatum by impulse flow and uptake. Brain Res Brain Res Rev 15:135-144. CrossRef Medline

Yorgason JT, España RA, Jones SR (2011) Demon voltammetry and analysis software: analysis of cocaine-induced alterations in dopamine signaling using multiple kinetic measures. J Neurosci Methods 202:158-164. CrossRef Medline

Zhang L, Doyon WM, Clark JJ, Phillips PE, Dani JA (2009) Controls of tonic and phasic dopamine transmission in the dorsal and ventral striatum. Mol Pharmacol 76:396-404. CrossRef Medline 